\title{
ESTARES ORIGINÁRIOS XHOSA, DEVIRES ANCESTRAIS KAINGANG, SABERES AMBIENTAIS DAS TREZE AVÔS... E DE ALGUNS BRANCOS \\ (linhas de fuga aquém-além de todo exotismo...)
}

\author{
Alfredo Martin ${ }^{1}$ \\ Ana Isabel Crespo ${ }^{2}$ \\ Darci Emiliano ${ }^{3}$
}

Resumo: Frente à problemática das catástrofes ambientais, das predações culturais e dos etnocídios institucionalizados, tentam-se algumas propostas e reflexões a partir das lógicas dos povos originários, em diálogo com saberes ancestrais e brancos.

Palavras Chave: estares, devires, saberes povos originários.

\section{NATIVE XHOSA BEINGS, KAIGANG ANCESTRAL BECOMINGS, ENVIRONMENTAL KNOWLWDGE OF THE THIRTEEN \\ GRANDMOTHERS...AND OF SOME WHITE PEOPLE}

(lines of flight within and beyond all exoticism...)

Abstract: Having in mind the environmental disasters, the cultural depredations and the institutionalized ethnocide(s), we will try some proposals and thoughts according to the native people logics and in dialogue with their ancestral knowledge.

Keywords: Beings, becomings, knowledge, native people.

\section{PALAVRAS PRELIMINARES SOBRE RESISTÊNCIAS AOS ETNOCÍDIOS.}

Desaprender o que foi aprendido nas escolas e nas Universidades. Conectar-se com a perspectiva epistémica dos povos originários. Atrever-se a sonhar vários futuros diferentes numa continuidade histórica com sujeitos coletivos, incluindo a Natureza como sujeito de direito.

Só um critério é válido: a qualidade de ser vivo.

1 Psicólogo, Doutor em Ciências da Educação, Docente do Progama de Pós-Graduação em Educação Ambiental, da Fundação Universidade do Rio Grande (PPGEA/FURG/RS). Endereço eletrônico: martingen@ibest.com.br.

2 Psicóloga, psicoterapeuta, pesquisadora do Centro de Estudos das Migrações e Relações Interculturais (CEMRI), Universidade Aberta, Lisboa, Portugal. Endereço eletrônico: anaisfc52@gmail.com.

3 Kaingang, empregado Instituto Federal do RS (IFRS - Sertão — RS), Primeiro Mestrando Indígena em Educação Ambiental no PPGEA/FURG/RS. Endereço eletrônico: darci.emiliano@ sertao.ifrs.edu.br. 
Cultura $=$ cuidado de vida, na sua raiz etimológica (agricultura, cuidado da terra; puericultura, cuidado das crianças...)

Urgente: deslocar o lugar a partir do qual estes paradigmas são pensados, sair do nô gordiano epistemológico occidental através das linhas de fuga de virtualidades insospeitadas.

Podemos mergulhar em águas extra-paradigmáticas? As palavras ditas no V Encontro de Kujás ${ }^{4}$ ressoam:

[...] Marcado pelas narrativas, pelas memórias e reminiscências que compõem a figura dos $\mathrm{Ku}-$ jás... o $\mathrm{V}^{\mathrm{o}}$ Encontro emerge no contemporâneo como um contraponto às assimetrias em relação aos direitos existenciais desse grupo indígena Jé Meridional.. As danças, as pinturas, os cantos enérgicos que ecoam há milénios no planalto meridional, hoje dão o tom de nossa existência enquanto continuidade, identidade e resistência de um povo que habita esse território há milhares de anos antes do presente, antes de senhores de escravos, ricos e pobres, patrões e empregados... vivíamos soberanos, absolutos, com dignidade e liberdade numa lógica pautada no respeito à natureza e sobrenatureza.

A indignação, a dor, não querem, não podem calar:

[...] historicamente fomos silenciados, oprimidos, tivemos nossos sagrados espaços apropriados pelos "visitantes" indesejados onde a opção era a de aldeamentos diminutos ou a morte. Vimos nossas casas virarem cinza, nossas histórias e narrativas ridicularizadas e fomos entendidos como atrasados por quem pisava em nosso sagrado solo, nosso não no sentido patrimonial, mas como parte de nós.

Não é o património o que importa (como na sociedade branca), mas sim a ancestralidade e a natureza, bases dessas identidades que se reconstroem cada vez as mesmas e cada vez diferentes, depois de mais de cinco séculos de etnocídio impune.

[...] Vimos o caos se manifestar na sua forma mais atroz, e com ele a morte. De nossos guerreiros, dos nossos velhos, das nossas mulheres, muitas inclusive escravas do corpo gélido e desumano de quem nos caçava a esmo, nem mesmo as crianças escaparam das garras de quem se dizia civilizado.

Já sabemos: no paradigma branco, a oposição é civilização ou barbárie. É claro, os bárbaros são sempre os outros, os diferentes...nós somos os "civilizados", temos um estado, um governo, leis, bancos, academias, saberes, escritas. [...] Um país e um estado que se nega a admitir sua dívida histórica com os povos indígenas, um Estado que se “desenvolveu” e con-

4 Texto Final do V ${ }^{\mathbf{o}}$ Encontro de Kujás - Morro do Osso — Porto Alegre, 21/23 de novembro 2014, assinado por lideranças de 15 T.I. Comunicação pessoal. 
Pontos de Interrogação, v. 4, n. 2, jul./dez. 2014

Revista do Programa de Pós-Graduação em Crítica Cultural

Universidade do Estado da Bahia (UNEB), Campus II — Alagoinhas — BA

solidou sobre os corpos dos nossos antepassados, onde o progresso e ambição lhe confere as mãos manchadas de sangue de nosso irmãos.

Ordem e progresso...está escrito, cantado, aprendido, inscrito até nas células... Será que alguma virtualidade poderá se atualizar nos entre-lugares paradigmáticos?

[...] Porém, aqui nesses dias e no improviso das estruturas, resignificamos nossa luta e resistência, balizados na figura dos Kujás, interpretado por muitos como eixo semântico na organização sociopolítica kaingang... é o lugar virtual em que se articulam os polos opostos criadores da significação... o Kujá transita e totaliza nas supostas posições das metades [Kamé/Kairu],que são inexoravelmente indissociáveis, e entre medicina tradicional, tradutor das falas da floresta, dançador, cantor e contador de histórias nostálgicas de nosso povo... essa figura é símbolo de nossa resistência.

Escutamos o seu Jorge Garcia, Kujã Kaingang de 96 anos: [...] Não sei escrever meu nome...mas compreendo a linguagem dos pássaros..falo com as árvores..nunca cobrei nada por curar..

Nem propriedade da terra, nem diplomas, nem honorários... outra lógica de vida é possível... Como, onde, com quem se apreende essa língua animal-vegetal-humana?

Precisamente nesses dias, ainda outra velha/nova tragédia entristeceu as comunidades: [...] exigimos um basta na criminalização das lideranças, que sejam feitas investigações sólidas nos crimes contra indígenas, como o caso do professor indígena de Vicente Dutra..na T.I. Kanóia, que deixou a comunidade em estado de choque..

Ainda existem bugreiros no século XXI... aqui bem perto de nós... bugreiros de pistolão e gravata... que querem se apropriar da terra para prostituí-la em mercadoria e logo aniquilá-la... nos aniquilando, de passagem, junto com os rios cheios de mercúrio, as capas freáticas com agroquímicos, a biodiversidade padronizada e uniformizada com manipulações genéticas cinco estrelas. Civilização...Ordem...Progresso...

Desta linha dura etnocida, deste paradigma suicidário, queremos sair, [...] dimensionar aqui a cultura Kaingang latente nas atuais gerações, como já existiu e continua a existir, que busca no passado os sentidos da existência e respostas para constituir um bem viver indígena. Este que repousa na demarcação das terras indígenas.

Território não é só terra...é também ancestralidade, espíritos, comunidade humana, existências, futuro... 
Fazer buracos nas paredes, inventar frestas... conexões inesperadas... rizomas criadores... passagens do ser em si como identidade fechada para os estares como devires em processos... precisamos de novas linhas de fuga, de novos territórios existenciais possíveis, de vida...

\section{LINHA UM: ESTARES UBUNTU...}

Um antropólogo propôs um jogo às crianças de uma tribo africana. Colocou uma cesta cheia de frutas perto de uma árvore e falou:

- Aquele de vocês que chegue primeiro, ganha todas essas frutas. Quando o antropólogo deu o sinal de partida, todas as crianças se tomaram pelas mãos e correram juntas; logo se sentaram a comer compartilhando o prêmio.

Ao perguntar o porquê de eles terem corrido assim, se só um poderia ganhar o prêmio para si próprio, eles responderam:

\section{- UBUNTU!!!}

O coitado do antropólogo não sabia que, em língua Xhosa (a mesma de Mandela), isso quer dizer: "Como um de nós poderia ganhar e estar feliz, se todos os outros estivessem tristes... Eu sou, porque nós somos..." Este conceito africano tradicional, usado também pelos zulus, poderia ser traduzido como "humanidade com os outros"; "uma pessoa devém humana através das outras pessoas".

Assim, parafraseando Desmond Tutu:

"Uma pessoa com UBUNTU é aberta e disponível para ou outros, não se sente ameaçada quando os outros são capazes e bons em alguma coisa e ela está segura de si própria porque sabe que pertence a uma grande totalidade; se sente diminuir quando as outras pessoas são humilhadas ou menosprezadas, torturadas ou oprimidas..."

Essa definição se complementa com um ditado popular zulu: “Umuntu, nigumuntu, nagamuntu”, que completa o conceito: uma pessoa é uma pessoa por causa dos outros.

Esta íntima relação outros-eu, geratriz dos vínculos socio-históricos, etno-grupais, político-existenciais, se mantém ao longo da vida e ela mantém a vida em todas suas formas, a "outredade" nos funda e constitui os fluxos dos nossos estares humanos. Essa "outredade" institui, no mais profundo de nós mesmos, muito mais que uma identidade fechada sobre si 
própria, que uma raiz única plantada num pedacinho de terra; ela cria e recria aberturas sem fim, rizomas multiconectados que incluem outras territorialidades animais, vegetais, minerais, cosmológicas. Sabemos o valor máximo que a terra tem para os povos originários, não porque ela seja deles (ninguém tinha títulos de propriedade quando os europeus invadiram o continente dito americano), mas porque eles são dela.

Eles e nós também, só que a gente branca ainda não se deu conta, ainda somos civilizados demais, ainda identitários demais, ainda tomamos por base nossas pequenas privacidades (título de propriedade, de eleitor, de conta bancária, de carro, de diplomas...), ainda colonialistas demais (sobretudo no nosso inconsciente), ainda consideramos a "outredade" como inimiga a vencer e dominar. As outras pessoas são rivais a vencer, a terra dos outros é possibilidade de lucro, se conseguimos fazer do mato vivo um plantio de transgênicos esterilizantes da biodiversidade, dos rios uma represa hidroelétrica devastadora de sítios ancestrais... Quando a terra é transmutada em mercadoria, ela morre, nós morremos com ela. Não sabemos estar humanos como mais um fluxo nas multiplicidades da vida.

Nossos povos originários (e originadores) não se sentiam indivíduos-ego-isoladosdonos-de-um-pedacinho-de-terra; as territorialidades indígenas não terminam no arame farpado, ainda menos nas fronteiras ditas nacionais...Na cosmologia guarani, a Terra sem Males não são hectares fixos num topos delimitado; ela é sobretudo um u-topos, um estar-viverlugar ainda-sempre em devir, um "Suma qamaña” (viver bem).

Um "sentipensar" que combina a mente com o coração. Um "sentipensar" em conexão íntima com a terra. Terra minha: não te afastes de mim, não me faltes / Por mais longe que vá. (Canto da Terra dos Índios da Pampa in Rosa do Mundo, Assírio e Alvim, Lisboa, 2001).

Eles não são originários só no sentido temporal, proto-histórico, mas também e sobretudo originadores de novas formas de existência social e de vida ecológica, eles são os povos do futuro. Nós brancos somos capazes de voar até à Lua e Marte, eles são capazes de cuidar da Terra e impedir que ela seja destruída por nós. Se puder haver uma humanidade sobrevivente aos cataclismos ambientais, ela será originada pelos povos originários. 


\section{LINHA DOIS: DEVIRES ANCESTRAIS, NAS PALAVRAS DE DARCI EMILIANO, DO POVO ORIGINÁRIO KAINGANG...}

Eu não só penso, sinto e vivo intensamente a minha identidade indígena, é necessário que se diga: o índio estando dentro ou fora da terra indígena ele jamais deixará de ser índio [...] A minha primeira escola (1978) foi a escola indígena localizada na própria TI. Nela cursei os quatro primeiros anos do Ensino Fundamental. Nestas séries enfatizavam mais o estudo do idioma Kaingang onde aprendíamos a ler, escrever e falar o idioma, o que hoje percebo como um diferencial e como um vínculo indissolúvel com a minha cultura [...] também me recordo dos momentos de alegria, quando desfrutava de frutas nativas ou silvestres, tais como: guabiroba, pitangueira, ariticum, sete-capotes, butiá, guaviju, ovaia, pinhão, cereja, amora do mato etc. Muitas vezes era a minha refeição diária. Lembro-me, igualmente, dos chás que minha mãe preparava (cidreira, hortelã, marcela, carqueja, cipó mil home, folha de laranjeira entre outros). Estes ajudavam a curar não só as dores físicas, mas espirituais, pois preparar um chá para alguém é um gesto de afeição [...] as duas preocupações que hoje se colocam como desafios no sentido de planejarmos o que fazer:

- $1^{\mathrm{a}}$. O que pode ser feito para que os saberes aprendidos e ainda praticados pelos kaingangs mais velhos sobre as plantas medicinais sejam transmitidos e incorporados como prática pelas novas gerações?

- $2^{\mathrm{a}}$. Manter os saberes das plantas medicinais na visão de mundo kaingang, que ainda tem como epicentro do seu pensamento a floresta, ou seja, há que se problematizar sobre determinados projetos que não favorecem a comunidade e tão pouco dialogam com aspectos culturais que devem ser valorizados e que nas relações interculturais com os não indígenas pode ser o que de mais importante os kaingangs podem compartilhar [...]. O que pode acontecer é que alguns índios percam o interesse no conhecimento das práticas culturais, mas não somente eles, pois há muitos casos em que mesmo aqueles morando nas T. I., fora de cidades estão com dificuldades em manter as práticas culturais e também o idioma sendo substituído pelo português, e também não reconhecendo seu Pertencimento e Identidade [...] essa busca constante que faço na inclusão na Educação é para tentar com que meus parentes (expressão utilizada para falar de índios de maneira geral, que compreende os de sua etnia e demais), fosse para proporcionar uma vida mais digna para a comunidade, que historicamente vem sofrendo com as mazelas da sociedade, são governos que vem e vão mas que ignoram que 
Pontos de Interrogação, v. 4, n. 2, jul./dez. 2014

Revista do Programa de Pós-Graduação em Crítica Cultural

Universidade do Estado da Bahia (UNEB), Campus II — Alagoinhas — BA

esta terra já era habitada pelos meus ancestrais quando os seus aqui chegaram [...] sei que estou numa luta, que muitas vezes é necessário que eu sendo Indio e que atua em um Órgão da Educação, e sendo único nos IFES, se faça presente e fale da sua cultura de maneira geral, fazendo trocas com companheiros da causa, meus colegas Negros, me aconselhando da necessidade de dar visibilidade a nível Nacional da presença Indígena como servidor e também com a chegada de alunos Indígenas nos IFES [...] acredito que quando da questão de se modificando ao longo do tempo com o contato do branco, foi e está ainda sendo de valia, pois o fato de poder transitar neste meio e por parte deste povo, é difícil sim, mas necessário que alguém num primeiro momento passe por isso, para novos guerreiros venham e que se sintam abraçados e acolhidos, pois nos ser também incentivado nesta notoriedade indígena, contrapor as falácias e ideias distorcidas como por exemplo índio é: vagabundo, bêbado, preguiçoso, ladrão, etc., eu acho que se houve mudança no meu modo de ser e viver neste meio externo foi que de certa forma me torno escravo do sistema, tendo que cumprir normas préestabelecidas, lidar com dinheiro, ser controlado pelo relógio, e tentar reverter o conceito que tinham de meu povo. Nos dias de hoje e de sempre são poucos os que se identificam com a causa indígena, digo isso pois com a recente possibilidade de inclusão na educação através de cotas [...] a forma de pensar e viver o meio ambiente, esta impregnada no pensar e agir indígena, mas que se faz necessário uma reciclagem dos saberes é como Guattari afirma de que ocorra as micro-intervenções ${ }^{5}$, vejo essa atitude também necessária dentro das terras indígenas no trato com lixos domésticos, plantações de sementes transgênicas, monoculturas querendo ser implantadas, margens de rios, lagos e nascentes, etc. Com essas atitudes vem de encontro com a escrita de Marcos Reigota a ética na lida com o meio ambiente sustentável. Esse é o diferencial do pensar do homem branco á "ética", falta de "ganancia" penso na geração, meus descendentes o que posso deixar para que eles possam usufruir deste meio com respeito a natureza de maneira geral. Como dizia o Kujá Jorge Garcia com o qual compartilho de que a mata significa tudo de sagrado para o índio inclusive a nossa religião, justo o que o povo não indígena não respeita. Volta citar a fala de Rogério Rosa quando diz, pensem se eu índio for derrubar a Igreja e o Cemitério onde estão seus antepassados certamente vcs não gostariam, é o que estão fazendo com o meu povo [...] o pensar de vir branco, penso que não interessa a etnia a que vc pertença, religião e cor de sua pele, mas sim as atitudes que deves

5 Em referência às revoluções moleculares propostas por Félix Guattari no seu livro As três ecologias. 
Pontos de Interrogação, v. 4, n. 2, jul./dez. 2014

Revista do Programa de Pós-Graduação em Crítica Cultural

Universidade do Estado da Bahia (UNEB), Campus II - Alagoinhas - BA

ter com o próximo e principalmente com a natureza o respeito com povos...hoje felizmente sou da etnia Kaingang, e pela trajetória desses de lutas e lutas, mas que também é um povo feliz a seu modo [...] me sinto muitas vezes sozinho nesta caminhada sofro me emociono como estou neste momento $14 \mathrm{HS}$ num quarto de hotel no centro de $\mathrm{BH}$, com tudo pago, passagens aéreas, diárias, alimentação, transporte, etc. mas que isso tudo que falo de conforto não me significa nada. Me questiono e se eu estivesse dentro de uma terra indígena, teria essas condições financeira facilitada? Pois o que tenho notado das terras indígenas digo lideres que desejam representar seu povo esbarram no financeiro acabam por não participarem de eventos de importância em beneficio de seu povo. Então estando no IFS, tenho participado de inúmeros eventos e como digo quando falam de índio é necessário que este esteja presente [...] eu acho que eu deveria me sentir um pouco privilegiado, podendo transitar em dois meios, mas a necessidade de adquirir algum conhecimento e munir e ou na busca de auxílio para amenizar problemas da etnia, penso que se em algum momento, nenhum indígena tivesse se arriscado na busca de algo novo, como por ex: minha luta de mais de duas décadas pelo ingresso e permanência dos índios nos IFS - Institutos Federais da Educação, neste momento eles não estariam nos IFS, pois esse processo é recente, fim de semana agora estamos indo para o terceiro processo seletivo através de cotas, acho que é preciso mais indígena em todas as áreas: na educação, saúde, direito, docentes, etc. e de repente com o Doutorado concluído penso em voltar para uma terra indígena, mas para isso devo conversar com diversas lideranças, para ver se já seria tempo de eu voltar ou continuar entre IFS, auxiliando as terras indígenas de maneira geral $[\ldots]$ em nenhum momento me sinto em dupla situação, a minha identidade e pertencimento a minha origem se fortalece a cada momento, a cada instante em que algo esteja acontecendo de exploração do meio ambiente, discriminação, preconceito, a cada morte de um parente na luta por seus direitos, e por que não dizer a cada evento de revitalização provando de que existe resistência de um povo.

O direito do ambiente não é um direito do homem sobre o ambiente, mas um direito do ambiente sobre o homem. Se os direitos do homem como ser vivo acabam a partir do momento em que ele pode prejudicar outras espécies, temos que pensar-atuar em função dos direitos à vida da Vida; assim, a Humanidade não se restringe aos homens e mulheres, ela é qualidade de todos os seres viventes.

Por muito diferentes que estas últimas sociedades sejam umas das outras, elas concordam em fazer do homem uma parte integrante e não o senhor da Criação. Através de sábios costumes, que faría- 
mos muito mal em relegar para a categoria de superstições, elas limitam o consumo de outras espécies vivas e impõem a este o respeito moral, associado a regras muito estritas, para assegurarem a sua conservação. (LÉVI-STRAUSS, 2010: 392-393).

No conceito de Perspectivismo, de Viveiros de Castro (2011), estão também implícitas estas ideias, quando ele afirma a auto-percepção como humano de todos os animais da floresta.

\section{LINHA TRÊS: OS SABERES AMBIENTAIS DAS TREZE AVÔS}

Como seria o sistema-mundo se deslocássemos o locus de enunciação do homem europeu para as mulheres indígenas das Américas? Será que as Indígenas idosas podem aconselhar o mundo? Vamos contar um conto para vocês:

Em um vale mágico, protegido pelos espíritos ancestrais, foi aceso um fogo; a chama que deu vida aquele fogo sagrado foi acesa em frente ao prédio das Nações Unidas. Essa tocha da paz viajou à volta do mundo atravessando sessenta e dois países e foi vista por milhões de pessoas durante essa milagrosa viagem. Ao redor daquela mesma chama se reuniram, numa noite de meados de outubro de 2004, treze vovôs indígenas... foi um momento histórico sem precedentes. Eram mulheres guardiãs dos ensinamentos das suas tribos, desde tempos imemoriais, e que tinham vindo de todas as partes do mundo. Todas elas tinham sido convidadas há muito tempo, num momento em que não existia o tempo como o conhecemos hoje, para se reunirem no momento da grande mudança e se converterem em uma grande força de paz no mundo. Segundo a profecia, elas deviam compartilhar seus segredos mais sagrados com as mesmas pessoas que as tinham oprimido, dado que a sobrevivência do planeta está em jogo. Eis o que elas disseram:

[...] Somos treze avós indígenas que nos reunimos pela primeira vez; chegamos dos quatro pontos cardiais e nos reunimos porque temos uma visão em comum para formar uma nova aliança global. Representamos tribos do Círculo Polar Ártico, da América do Norte, do Sul e Central, da África, do Tibet e do Nepal.

Estamos muito preocupadas com a destruição sem precedentes que esta sofrendo nossa Mãe Terra, a contaminação do nosso ar, da nossa água e do nosso solo, com as atrocidades das guerras, o flagelo da pobreza, a ameaça das armas e do lixo nuclear, a cultura do materialismo, as epidemias...

Nós, o Conselho Internacional das treze Avós Indígenas, acreditamos que nossas formas ancestrais de oração, conciliação e cura são de vital importância. Reunimo-nos para educar e ensinar às nossas criaturas, unimo-nos para resgatar a prática de nossas cerimônias e reafirmar o direito a utilizar nossas plantas medicinais. Unimo-nos a todas/os aqueles que honram à Criadora e a todas/os aqueles que trabalham e rezam pela Paz mundial e a cura de nossa Mãe. (La voz de las Trece Abuelas. 
Carol Schaefer. Edit Luciérnaga — in La agenda de las Mujeres-activistas por La Paz, Horas y Horas, Madrid, 2011)

Nunca esquecemos que aqui, antes de 1492, também havia um patriarcado. Nós inscrevemo-nos nas lutas ancestrais das mulheres perante um patriarcado que nos oprimia e nos oprime (ibid.)

A pergunta é: no sistema moderno colonial de género, pode haver processos de descolonização sem despratiarcalização, visto serem sistemas de opressão que operaram entrelaçados durante mais de cinco séculos e que compartem mecanismos de controle e submissão?

O que pode dizer a respeito nossa antropologia branca? Retomando o estudo de Clastres (2003), Viveiros de Castro (2011:346), numa nota de rodapé do seu pós-facio que, em nossa opinião, bem mereceria estar incluída no texto principal, aponta:

[...] Clastres afirma, de modo um tanto surpreendente, que as mulheres são as senhoras da sociedade primitiva, enquanto os homens são servidores desta mesma sociedade. Os homens talvez controlem imediatamente as mulheres; mas estas controlam, em última análise, a sociedade que, por sua vez, controla os homens. Metacontrole.

Será que dentro desta "surpresa" e deste "metacontrole" pode haver uma fresta, uma linha de fuga, uma virtualidade que nos permita evitar, mesmo no último minuto que seja, nosso suicídio coletivo? Escutemos uma história quechua do sábio Macua, da Bolívia:

Um macaco chamado Norte passeia na floresta e no lago vê um peixe chamado Sul. O macaco Norte diz: coitado está quase a afogar-se na água. O macaco tira o peixe da água que começa a dançar e segue o seu caminho. Volta e vê o peixe morto e diz: pelo menos ele não morreu afogado. Segue feliz.

Para onde aponta nossa bússola? "Nortear” já é uma direção semântica instituída... seremos capazes de aprender a "sudear"?

\section{LINHA QUATRO: PALAVRAS YANOMAMI.}

Davi Kopenawa Yanomani diz:

Os brancos com a sua ganância por minério podem provocar uma nova queda do céu. Rasparam a pele da terra. Estragam os rios. Veio a doença, gripe, sarampo, tuberculose, cancro. O garimpeiro, o fazendeiro, trabalhadores rurais derrubando e matando. Vocês, não-índios, destroem. A poluição está lá em cima e muda o tempo. O nosso trabalho de pajé é entrar em contacto com o trovão, o 
espírito da terra. O coração da terra está na terra. A terra é a prioridade. (KOPENAWA, exposição $\operatorname{oral}^{6}$ ).

\section{LINHA CINCO: PALAVRAS DE BRANCO}

[...] algo como a expressão mais comovedora e mais verdadeira da ternura humana" (Levy-Strauss, 1986:277-278).

Entre os Yanomani não tinha (havia) a dominação como nos não-indígenas. Encontrei-me como pessoa. (Claudia Andujar, fotógrafa de origem ucraniana, relatando suas vivências com o povo originário Yanomami, na FLIP 2014).

\section{LINHA SEIS: NOVAS PALAVRAS DE DARCI EMILIANO, KAINGANG:}

Quando diz que tanto mal tem nos feitos, digo que não é somente para nós que eles cometem, mas também entre irmãos e entre eles mesmos, não respeitam o meio ambiente, destroem, maltratam, vendem sua própria mãe "TERRA" e, não pensam nos seus descendentes o que restará para estes? Se eu pudesse fazer mágicas: como o sistema esta aí "capitalismo" digo a cada árvore derrubada, a cada parente morto se revertesse em dinheiro para investir em recuperação do meio, e ainda propor uma educação ambiental a esse povo destruidor, houvesse uma sociedade melhor, com consciência de causa, pudessem respeitar e viver multiplicidade de experiências, interação entre homens e mulheres, uma sociedade melhor em harmonia.

\section{REFERÊNCIAS}

CLASTRES, Pierre. A sociedade contra o estado.Trad. Theo Santiago. São Paulo: Cossac Naify, 2003.

GUATTARI, Félix. As Três Ecologias. Trad. M.C. F. Bittencourt. $3^{\text {a }}$ Edição. Campinas: Papirus, 1991.

LÉVI-STRAUSS, Claude. Olhar distanciado, Lisboa: Edições 70 Ltda, 2010. Tristes Trópicos, Lisboa: Edições 70 Ltda, 1986.

VIVEIROS DE CASTRO, Eduardo. Métaphysiques canibales.Paris:Payot, 2009.

Recebido em: 19 de outubro de 2014.

Aceito em: 20 de novembro de 2014.

6 Encontro de Kujás e Caciques, Gravação vídeo-documental LAPSICOT (Laboratório de Psicologia Institucional, Comunitária e Transcultural) — FURG, 2012. 
